\title{
BMJ Open Conservative treatment of adhesive small bowel obstruction in children: a systematic review
}

\author{
Lung-Huang Lin, ${ }^{1,2}$ Chee-Yew Lee, ${ }^{1}$ Min-Hsuan Hung, ${ }^{3}$ Der-Fang Chen ${ }^{4}$
}

To cite: Lin L-H, Lee C-Y, Hung $\mathrm{M}-\mathrm{H}$, et al. Conservative treatment of adhesive small bowel obstruction in children: a systematic review. BMJ Open 2014;4:e005789. doi:10.1136/bmjopen-2014005789

- Prepublication history and additional material is available. To view please visit the journal (http://dx.doi.org/ 10.1136/bmjopen-2014005789)

Received 27 May 2014 Revised 20 August 2014 Accepted 27 August 2014

CrossMark

${ }^{1}$ Departments of Pediatrics, Cathay General Hospital, Taipei, Taiwan

${ }^{2}$ School of Medicine, FuJen Catholic University, New Taipei City, Taiwan ${ }^{3}$ Department of Pediatrics, Song-Shan Armed Forces General Hospital, Taipei, Taiwan

${ }^{4}$ Department of Surgery, Cathay General Hospital, Taipei, Taiwan

Correspondence to Dr Lung-Huang Lin; LHLINLH@yahoo.com.tw

\section{ABSTRACT}

Objective: To assess the effectiveness of conservative treatment for adhesive small bowel obstruction (ASBO) in children.

Design: Systematic review of studies involved children with ASBO who received initial conservative/nonoperative treatment.

Setting: The search was performed in April 2013 using PubMed (see online supplementary file 1), current contents, and the Cochrane database.

Participants: Children with ASBO.

Interventions: Conservative treatment included nasogastric decompression, parenteral fluids and correction of electrolyte and fluid imbalance.

Primary outcome: Treatment success.

Secondary outcomes: Length of hospital stay and the time to first feeding after hospital admission.

Results: 7 studies (six retrospective, one prospective), involving 8-109 patients (age: 1 month to 16 years) treated conservatively, were included in the review. The nature of conservative treatment was generally consistent between studies (nasogastric decompression, parenteral fluids and correction of electrolyte and fluid imbalance), although patients in one study also received Gastrografin. The rate of conservative treatment success ranged from $16 \%$ to $75 \%$ among the five studies, but one trial showed $0 \%$ successful rate. The hospital length of stay ranged from 3 to 6.5 days for conservative treatment (vs 10.2-13 days for operative treatment). The time to first feeding ranged from 31 to $84 \mathrm{~h}$ for conservative treatment.

Conclusions: In conclusion, in the majority of cases, conservative treatment is an effective means of managing ASBO in children.

\section{INTRODUCTION}

Adhesions following abdominal surgery are a common cause of small bowel obstruction (SBO) in adults. ${ }^{1}{ }^{2}$ Indeed, adhesions have been reported to account for approximately $70 \%$ of cases of $\mathrm{SBO}$ in adults, ${ }^{3}$ with up to $25 \%$ of patients who undergo abdominal surgery subsequently developing adhesive SBO (ASBO). ${ }^{1}$ There is less information available on ASBO in children; however, the

\section{Strengths and limitations of this study}

- Conservative treatment was successful in more than $50 \%$ of children with adhesive small bowel obstruction in the four of the seven included studies.

- All but one of the included studies were retrospective in design.

- There was some variability between studies regarding the conservative treatment regimens.

available data suggest that from $1 \%$ to $9 \%$ of children will experience ASBO after abdominal surgery. ${ }^{4-7}$ As ASBO can lead to morbidity and mortality, and has high associated socioeconomic costs, effective treatment is essential. $^{12}$

Treatment for ASBO may be operative or conservative/non-operative. Operative treatment, adhesiolysis through laparoscopic or open approaches, can be effective (and essential in some cases ie, those involving strangulation), but carries a risk of associated morbidity and mortality. ${ }^{8-10}$ Various conservative means of managing ASBO have been reported, including nasogastric tube suction and fluid resuscitation, and administration of water-soluble contrast agents, such as gastrografin, which may also serve to determine the need for surgery. ${ }^{211}$ In adults, conservative treatment of ASBO is frequently used and has been found to be effective in a relatively large, but somewhat variable (approximately $40 \%$ to $70 \%$ ), proportion of cases. ${ }^{12-15}$ There is less definitive information available concerning the effectiveness of conservative treatment in children with ASBO, although effectiveness rates ranging from approximately $16-60 \%$ have been reported. ${ }^{16-19}$ The ASBO guidelines published in 2013 provide no specific guidance for the treatment of children. ${ }^{20}$ In general, there is a lack of consensus, or indeed available guidelines, on the management of ASBO in children. 
To obtain further information on the effectiveness of conservative treatment for ASBO in children, we performed a systematic review of the literature.

\section{METHODS}

\section{Search strategy}

The search was performed in August 2014 PubMed (see online supplementary file 1), Current Contents, and the Cochrane database were searched using different combinations of the following key terms: small bowel, obstruction, adhesion, children/paediatric, conservative treatment and the water-soluble contrast agent, Gastrografin. Reference lists of pertinent articles were hand searched, where appropriate, to identify other potentially relevant studies. The search strategy is detailed in online supplementary file for the search in PubMed (see online supplementary file 1).

\section{Selection of studies}

Studies were included in the systematic review if they involved paediatric patients (from birth up to 18 years of age) who were diagnosed as ASBO and received conservative treatment. The diagnostic criteria included abdominal pain/distention, nausea/vomiting, failure to pass flatus and stool and showed an air-fluid level on plain erect abdominal radiographs. Conservative treatment included nasogastric decompression, parenteral fluids and correction of electrolyte and fluid imbalance. Clinical report of paediatric patients managed with water-soluble contrast medium (ie, Gastrografin) was also included. Studies were excluded from the systematic review if they included adults, not related to ASBO, surgical management only, non-interventional study, no quantitative outcomes or outcomes did not include rate of treatment success (surgery not required) or non-English language article.

\section{Data extraction}

Data were extracted from articles by two independent reviewers. Disagreement between these reviewers was resolved by consulting with a third reviewer. The following information/data were extracted from studies that met the eligibility criteria: author details, year of publication, study design, primary surgical condition leading to the development of adhesions, treatment groups, conservative treatment details, age and sex of patients, treatment success (ie, proportion of patients treated conservatively who did not require subsequent surgical treatment for ASBO), recurrence of ASBO, hospital length of stay, time to first feeding after hospital admission and complications of treatment.

\section{Outcome measures}

The primary outcome measure was treatment success. Secondary outcomes were hospital length of stay, the time to first feeding after hospital admission, the proportion of patients who experienced ASBO recurrence and the proportion of patients experiencing complications of after treatment.

\section{Quality assessments}

The Newcastle-Ottawa Quality Assessment scale was used to assess the quality of this review. The included studies were assessed on three dimensions: selection, comparability and outcome (for cohort studies) or exposure (for case-control studies). The star system was used to semiquantification of the study quality.

\section{RESULTS}

\section{Study selection}

A total of 266 articles were identified in the initial literature search, and 22 articles were included in full-text review (figure 1). Of these, 15 were found to be no quantitative outcome or outcome did not include rate of treatment success (surgery not required). Hence, a total of seven articles ${ }^{16-19}$ 21-23 $^{2}$ underwent full-text review. All were found to be eligible for inclusion into our systematic review.

\section{Study characteristics}

The characteristics of the studies included in our systematic review are summarised in (table 1). The studies were conducted in several different countries. Of note, all but one of the studies was retrospective in design. The only exception was the study reported by Bonnard et $a l^{21}$ which was a prospective, case-control study. Appendicitis and intussusception were common primary

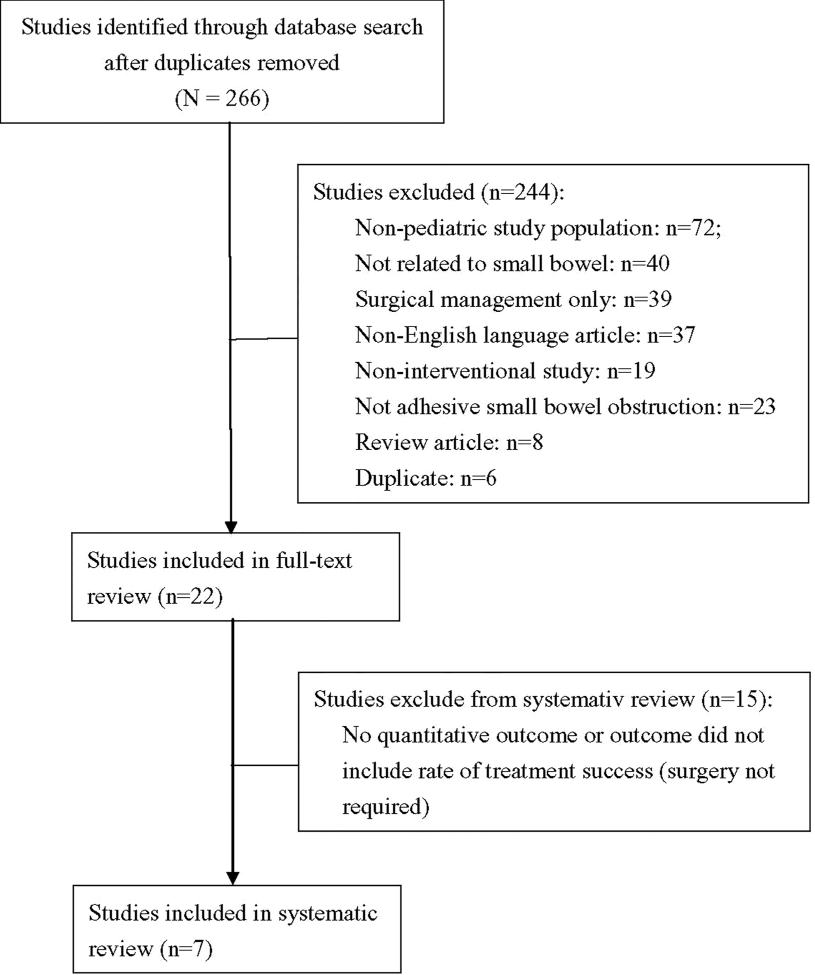

Figure 1 Flow diagram of study selection. 


\begin{tabular}{|c|c|c|c|c|c|c|c|}
\hline First author (year) & Type of study & Country & Primary condition & Treatment group(s) & Conservative treatment & Age of patients & Sex \\
\hline Akgür (1991) & $\begin{array}{l}\text { Retrospective } \\
\text { (cohort) }\end{array}$ & Turkey & $\begin{array}{l}\text { Appendicitis, abdominal trauma, } \\
\text { intraperitoneal/retroperitoneal } \\
\text { malignancy, intussusception, } \\
\text { laparotomy, colonic pull-through } \\
\text { surgery }\end{array}$ & $\begin{array}{l}\text { Conservative: } n=149 \\
\text { episodes } \\
\text { Operative: } n=81 \\
\text { episodes }\end{array}$ & $\begin{array}{l}\text { Nasogastric decompression, } \\
\text { parenteral fluid, electrolyte } \\
\text { resuscitation and } \\
\text { maintenance, and restriction } \\
\text { of analgesics and antibiotics }\end{array}$ & 1 month to 16 years & $60 \mathrm{~F} / 121 \mathrm{M}$ \\
\hline Bonnard (2011) & $\begin{array}{l}\text { Prospective } \\
\text { (case control) }\end{array}$ & France & $\begin{array}{l}\text { Appendicitis, neonatal surgical } \\
\text { conditions }\end{array}$ & $\begin{array}{l}\text { Conservative: } n=8 \\
\text { Control: } n=16\end{array}$ & $\begin{array}{l}\text { Nasogastric decompression, } \\
\text { bolus and infused isotonic } \\
\text { saline, followed by } 50- \\
100 \mathrm{~mL} \text { Gastrografin. } \\
\text { Control patients were treated } \\
\text { as above without } \\
\text { Gastrografin }\end{array}$ & $\begin{array}{l}\text { Conservative: } \\
1.2 \text { years (range: } \\
0.5-4.1 \text { ) } \\
\text { Control: } 3 \text { years } \\
\text { (range: } 0.3-8.7 \text { ) }\end{array}$ & $\begin{array}{l}\text { Conservative:4F/ } \\
4 \mathrm{M} \\
\text { Control: } 9 \mathrm{~F} / 7 \mathrm{M}\end{array}$ \\
\hline Eeson (2010) & $\begin{array}{l}\text { Retrospective } \\
\text { (cohort) }\end{array}$ & Canada & $\begin{array}{l}\text { Appendicitis, colostomy, Ladd's } \\
\text { procedure, Nissen fundoplication, } \\
\text { congenital abdominal wall defect } \\
\text { repair, reversal of stoma, congenital } \\
\text { diaphragmatic hernia repair, } \\
\text { colectomy, ileostomy, gastrostomy, } \\
\text { nephrectomy }\end{array}$ & $\begin{array}{l}\text { Conservative: } n=26 \\
\text { Delayed operative: } \\
n=107 \\
\text { Operative: } n=32\end{array}$ & $\begin{array}{l}\text { Intravenous fluid } \\
\text { resuscitation, nasogastric, } \\
\text { decompression, and } \\
\text { intensive monitoring }\end{array}$ & $\begin{array}{l}\text { Conservative: } 9.1 \\
\pm 6.0 \text { years } \\
\text { Delayed operative: } \\
6.4 \pm 5.2 \text { years } \\
\text { Operative: } 5.2 \\
\pm 4.6 \text { years }\end{array}$ & $\begin{array}{l}\text { Conservative: } 7 \mathrm{~F} / \\
19 \mathrm{M} \\
\text { Delayed } \\
\text { operative: } 35 \mathrm{~F} / \\
75 \mathrm{M} \\
\text { Operative: } 9 \mathrm{~F} / \\
23 \mathrm{M}\end{array}$ \\
\hline Vijay (2005) & $\begin{array}{l}\text { Retrospective } \\
\text { (cohort) }\end{array}$ & India & $\begin{array}{l}\text { Hirschsprung's disease, } \\
\text { intussusception, appendicitis, } \\
\text { malrotation, Meckel's diverticulum, } \\
\text { anorectal malformation, atresia, } \\
\text { Wilm's tumour, eventration of } \\
\text { diaphragm, ischaemic enteritis }\end{array}$ & Conservative: $n=69$ & $\begin{array}{l}\text { Nasogastric decompression, } \\
\text { intravenous fluids, antibiotics, } \\
\text { and correction of electrolyte } \\
\text { imbalance }\end{array}$ & $\begin{array}{l}0-1 \text { years: } n=26 \\
1-5 \text { years: } n=19 \\
5-10 \text { years: } n=13 \\
10-13 \text { years: } n=11\end{array}$ & NA \\
\hline Osifo (2010) & $\begin{array}{l}\text { Retrospective } \\
\text { (cohort) }\end{array}$ & Nigeria & $\begin{array}{l}\text { Intussusception, perforated } \\
\text { appendix, perforated gut, abdominal } \\
\text { trauma, typhoid perforation, ovarian } \\
\text { cyst rupture, omphalocele closure }\end{array}$ & Conservative: $n=21$ & $\begin{array}{l}\text { Nasogastric decompression, } \\
\text { intravenous fluids, antibiotics, } \\
\text { and correction of electrolyte } \\
\text { imbalance }\end{array}$ & $3.0 \pm 6.4$ years & $8 \mathrm{~F} / 13 \mathrm{M}$ \\
\hline Feigin (2010) & $\begin{array}{l}\text { Retrospective } \\
\text { (cohort) }\end{array}$ & Israel & $\begin{array}{l}\text { Appendicitis, congenital bowel defect, } \\
\text { abdominal tumour, enterocolitis, } \\
\text { intussusception, meconium ileus, } \\
\text { stomach condition, malrotation, } \\
\text { genitourinary condition, abdominal } \\
\text { trauma }\end{array}$ & $\begin{array}{l}\text { Conservative: } n=109 \\
\text { Operative: } n=65\end{array}$ & $\begin{array}{l}\text { Nasogastric decompression, } \\
\text { parenteral fluids, and } \\
\text { correction of fluid and } \\
\text { electrolyte imbalance }\end{array}$ & $\begin{array}{l}\text { Conservative: } \\
8.3 \text { years } \\
\text { Operative: } 6.3 \text { years }\end{array}$ & NA \\
\hline Nasir (2013) & $\begin{array}{l}\text { Retrospective } \\
\text { (cohort) }\end{array}$ & Nigeria & $\begin{array}{l}\text { Typhoid intestinal perforation, } \\
\text { intussusceptions, intestinal } \\
\text { malrotation, appendicitis, blunt } \\
\text { abdominal injury with rupture viscus, } \\
\text { rupture omphalocele, gastroschisis, } \\
\text { Wilm's tumour, choledochal cyst, } \\
\text { mesentery cyst, obstructed hernia }\end{array}$ & $\begin{array}{l}\text { Conservative: } n=16 \\
\text { Operative: } n=18\end{array}$ & $\begin{array}{l}\text { Nasogastric decompression, } \\
\text { resuscitation with intravenous } \\
\text { fluid and correction of } \\
\text { electrolyte imbalance }\end{array}$ & $\begin{array}{l}\text { Conservative: } \\
5 \text { years } \\
\text { Operative: } 3 \text { years }\end{array}$ & $\begin{array}{l}\text { Conservative: } 4 \mathrm{~F} / \\
12 \mathrm{M} \\
\text { Operative: } 8 \mathrm{~F} / \\
10 \mathrm{M}\end{array}$ \\
\hline
\end{tabular}

F, female; M, male; m, month; NA, not available.

Table 1 Characteristics of studies included in the systematic review 
conditions requiring surgery (resulting in the development of adhesions) in all studies, although there were a considerable number of primary conditions necessitating surgery. The number of patients who underwent conservative treatment was variable between studies, ranging from 8 to 109 (note: Akgur et al ${ }^{19}$ reported the number of treatment episodes, rather than the number of patients). Four of the seven studies reported results for multiple treatment groups, including conservative and operative ${ }^{16} 17 \quad 23$ or conservative and control. ${ }^{21}$ There were two operative groups in the study reported by Eeson $e t a l,{ }^{17}$ a group of patients who received operative treatment shortly after admission, and a group of patients who received operative treatment after a period of initial conservative treatment. Both treatment groups in the study reported by Bonnard et $a l^{21}$ in effect involved conservative treatment, plus or minus the addition of Gastrografin. Otherwise, conservative treatment was generally consistent between studies, comprising nasogastric decompression, parenteral fluids, correction of electrolyte and fluid imbalances and monitoring. Parenteral nutrition was not provided to patients in the study reported by Osifo and Ovueni, ${ }^{22}$ nor did patients in this study receive intensive monitoring. The age of patients was quite variable, ranging from approximately 1 month up to 16 years of age. Generally, however, patients were less than 10 years of age. In four ${ }^{17} 192223$ of the seven studies, there were considerably more male than female patients.

\section{Outcomes}

All studies reported data on treatment success, four studies reported data on hospital length of stay, ${ }^{16} 172123$ and two studies reported data on the time to first feeding. ${ }^{1621}$ Data for the other outcomes, ASBO recurrence ${ }^{19}$ and complications ${ }^{17}{ }^{23}$ were also reported. The rate of treatment success ranged from $0 \%$ to $75 \%$, but was $>50 \%$ in four ${ }^{16} 181921$ of the seven studies. The hospital length of stay ranged from 3 to 6.5 days for patients who received conservative treatment. Unsurprisingly, the hospital length of stay was longer for patients who received operative treatment, ranging from 10.2 to 13 days. The time to first feeding ranged from 31 to $84 \mathrm{~h}$ for patients who received conservative treatment. All outcomes in the study reported by Bonnard et al favoured conservative treatment with Gastrografin over conservative treatment without Gastrografin. In the study reported by Akgur et $a l^{19}$ the rate of ASBO recurrence was lower with conservative compared with operative treatment, while in the study reported by Eeson et al, ${ }^{17}$ no patients who received conservative treatment experienced complications compared with more than $10 \%$ of patients who received operative treatment (table 2). Nasir et a $t^{23}$ reported there were no significant differences in sex $(\mathrm{p}=0.24)$, initial procedure ( $p=0.12)$, age (1825 vs 1095 days, $p=0.96)$, duration of symptoms ( 1 vs 2 days, $\mathrm{p}=0.32$ ), and time to readmission (275 vs 95 days, $\mathrm{p}=0.49$ ) between the patients who responded to non-operative management and those who underwent surgery. However, the length of hospital stay was significantly shorter in the non-operative patient group than the group that underwent surgery (5 vs 13 days, $\mathrm{p}<0.0001)$.

\section{Quality assessments}

All six cohort studies were representative of the average patient with ABSO (table 3). Exposure was ascertained from secure records and outcomes were linked to records for all studies. All six of these studies demonstrated that the outcome of interest was not present at the beginning of the study. The follow-up was adequate for outcomes to have occurred for all six cohort studies.

With regard to the case-control study, the case definition was adequate, there was some potential for selection bias, the controls were derived from the hospital, the assessment of exposure was derived from a secure record, and the same method was used for cases and controls to ascertain exposure (table 4 ).

\section{DISCUSSION}

The purpose of this systematic review was to summarise the available evidence on the use of conservative treatment for the management of ASBO in children. A total of seven studies (only one prospective in design) met the criteria for inclusion in our review. In general, the findings from these studies indicate that conservative treatment can be effective for treating ASBO in large proportion of children.

Of note, four of the seven studies ${ }^{1618} 1921$ included in our review reported that conservative treatment was successful in more than $50 \%$ of cases. This rate of conservative treatment success is similar to that reported in studies involving adults with ASBO. ${ }^{12-15}$ Furthermore, Nasir $e t a l^{23}$ found that hospital stay were significantly shorter in their group of patients that received conservative treatment compared with those who underwent surgery. Interestingly, conservative treatment was successful in none of the cases in the study reported by Osifo and Ovueni. ${ }^{22}$ This is surprising, given the otherwise overwhelming positive effects of conservative treatment. However, as acknowledged by the authors, ${ }^{22}$ the children in their study were treated in a resource poor country, which appears to have limited the capacity for comprehensive conservative treatment (including parenteral nutrition) and monitoring. Eeson $e t a l^{17}$ also reported a much lower rate of conservative treatment success $(16 \%)$ than reported in the other studies, ${ }^{16} 18 \quad 192123$ despite the use of a similar regimen. The reason for this much lower rate of treatment success is not readily apparent, but would suggest that children in the study may have had more severe ASBO than those in the other studies. Further studies are needed to identify the characteristics of children with ASBO who are most likely to respond positively to conservative treatment.

The conservative treatment regimens were, for the most part, consistent between studies, comprising 
Table 2 Summary of key outcomes and results for studies included in the systematic review

\begin{tabular}{|c|c|c|c|c|}
\hline $\begin{array}{l}\text { First author } \\
\text { (year) }\end{array}$ & $\begin{array}{l}\text { Key outcomes } \\
\text { assessed }\end{array}$ & $\begin{array}{l}\text { Treatment success } \\
\text { (primary outcome) }\end{array}$ & $\begin{array}{l}\text { Hospital length of } \\
\text { stay }\end{array}$ & Other outcomes \\
\hline Akgür (1991) & $\begin{array}{l}\text { Treatment success } \\
\text { (surgery not required) } \\
\text { Recurrence }\end{array}$ & Conservative: $73.8 \%$ & & $\begin{array}{l}\text { Recurrence } \\
\text { Conservative: } 36.5 \% \\
\text { Operative: } 18.8 \%\end{array}$ \\
\hline Bonnard (2011) & $\begin{array}{l}\text { Treatment success } \\
\text { (surgery not required) } \\
\text { Hospital length of stay } \\
\text { Time to first feeding }\end{array}$ & $\begin{array}{l}\text { Conservative: } 75 \% \\
\text { Control: } 50 \%\end{array}$ & $\begin{array}{l}\text { Conservative: } 3 \text { days } \\
\text { Control: } 6.5 \text { days }\end{array}$ & $\begin{array}{l}\text { Time to first feeding } \\
\text { Conservative: } 48 \mathrm{~h} \\
\text { Control: } 84 \mathrm{~h}\end{array}$ \\
\hline Eeson (2010) & $\begin{array}{l}\text { Treatment success } \\
\text { (surgery not required) } \\
\text { Hospital length of stay } \\
\text { Complications }\end{array}$ & Conservative: $16 \%$ & $\begin{array}{l}\text { Conservative: } \\
6.4 \pm 7.7 \text { days } \\
\text { Delayed operative: } \\
14.0 \pm 11.8 \text { days } \\
\text { Operative: } \\
10.4 \pm 8.9 \text { days }\end{array}$ & $\begin{array}{l}\text { Complications } \\
\text { Conservative: } 0 \% \\
\text { Delayed operative: } \\
11.2 \% \\
\text { Operative: } 12.5 \%\end{array}$ \\
\hline Vijay (2005) & $\begin{array}{l}\text { Treatment success } \\
\text { (surgery not required) }\end{array}$ & $\begin{array}{l}\text { Overall: } 52.2 \% \\
0-1 \text { y: } 26.9 \% \\
1-5 \text { y: } 73.7 \% \\
5-10 \text { y: } 61.5 \% \\
10-13 \text { y: } 63.6 \%\end{array}$ & & \\
\hline Osifo (2010) & $\begin{array}{l}\text { Treatment success } \\
\text { (surgery not required) }\end{array}$ & Conservative: $0 \%$ & & \\
\hline Feigin (2010) & $\begin{array}{l}\text { Treatment success } \\
\text { (surgery not required) } \\
\text { Hospital length of stay } \\
\text { Time to first feeding }\end{array}$ & Conservative: $63 \%$ & $\begin{array}{l}\text { Conservative: } 4.5 \text { days } \\
\text { Operative: } 10.2 \text { days }\end{array}$ & $\begin{array}{l}\text { Time to first feeding } \\
\text { Conservative: } 31 \mathrm{~h} \\
\text { Operative: } 95 \mathrm{~h}\end{array}$ \\
\hline Nasir (2013) & $\begin{array}{l}\text { Treatment success } \\
\text { (surgery not required) } \\
\text { Time to re-admission } \\
\text { Duration of symptoms } \\
\text { Hospital length of stay }\end{array}$ & Conservative: $37.5 \%$ & $\begin{array}{l}\text { Conservative: } \\
5 \text { (4-9.3) days } \\
\text { Operative: } \\
13(10-18.5) \text { days }\end{array}$ & $\begin{array}{l}\text { Time to re-admission } \\
\text { Conservative: } 27.5 \\
\text { (13.3-127.5) days } \\
\text { Operative: } 95 \text { (15-476) } \\
\text { days } \\
\text { Duration of symptoms } \\
\text { Conservative: } 1 \text { (1-3.5) } \\
\text { days } \\
\text { Operative: } 2(1-4) \text { aysd }\end{array}$ \\
\hline
\end{tabular}

nasogastric decompression, parenteral fluids and correction of electrolyte and fluid imbalances. Not all studies specified that children received parenteral nutrition, however, we assume that parenteral nutrition was provided as a matter of course in all but the study reported by Osifo and Ovueni. ${ }^{22}$ The findings reported by these investigators suggest that parenteral nutrition and intensive monitoring are an essential component of any conservative treatment regimen for ASBO in children.

Another unique treatment was the administration of Gastrografin after initial conservative management (as described above).$^{21}$ Water-soluble contrast material, such as Gastrografin, is safe and non-irritant to the peritoneal cavity of patients (including pediatric patients). ${ }^{24}$ Clinical trial conducted by Bonnard et $a l^{21}$ found that addition of Gastrografin to the conservative treatment regimen increased the rate of treatment success from $50 \%$ to $75 \%$. The use of water-soluble contrast agents has been much more comprehensively studied in adults with ASBO and have been consistently reported to improve rates of treatment success (ie, the lack of the requirement for surgery) compared with standard conservative treatment. ${ }^{11} 25$ Water-soluble contrast agent administration was effective in reducing the need for surgery and shortening hospital stay. ${ }^{11}$ However, the value of using water-soluble contrast material in therapeutic purpose is still controversial. A prospective, randomised clinical study was conducted to investigate the efficacy of using meglumine ioxitalamate, a water-soluble hyperosmotic iodine-containing contrast material, as a supplement to the standard conservative treatment of postoperative small-bowel obstruction. ${ }^{26}$ The author found that water-soluble contrast material offered no benefit as a supplement to the conservative treatment of small-bowel obstruction. Outcome of a meta-analysis indicated that water-soluble contrast (Gastrografin) did not reduce the need for surgical intervention but it did reduce the length of hospital stays compared with placebo. ${ }^{27}$ The value of water-soluble contrast agents in children in the management of ASBO is not known. 
Table 3 Newcastle-Ottawa quality assessment scale (Cohort study)

\begin{tabular}{lllllll}
\hline & Akgür & Eeson & Vijay & Osifo & Feigin & Nasir \\
First author (year) & $(1991)$ & $(2010)$ & $(2005)$ & $(2010)$ & $(2010)$ & $(2013)$ \\
\hline
\end{tabular}

\section{Selection}

1. Representativeness of the exposed cohort

A. Truly representative of the average patient with

ABSO in the community

B. Somewhat representative of the average_ in the community

C. Selected group of users ie, nurses, volunteers

D. No description of the derivation of the cohort

2. Selection of the non exposed cohort

A. Drawn from the same community as the exposed cohort

B. Drawn from a different source

C. No description of the derivation of the non exposed cohort

3. Ascertainment of exposure

A. Secure record (ie, surgical records)

B. Structured interview

C. Written self report

D. No description

4. Demonstration that outcome of interest was not present at start of study

A. Yes

B. No

Comparability

1. Comparability of cohorts on the basis of the design or analysis

A. Study controls for treatment

B. Study controls for any additional factor (this criteria could be modified to indicate specific control for a second important factor.)

Outcome

1. Assessment of outcome
A. Independent blind assessment
B. Record linkage
C. Self report
D. No description

2. Was follow-up long enough for outcomes to occur
A. Yes (select an adequate follow-up period for outcome of interest)
B. No

3. Adequacy of follow-up of cohorts

A. Complete follow-up-all participants accounted for

B. Subjects lost to follow-up unlikely to introduce biassmall number lost $\rightarrow$ _ $\%$ (select an adequate \%) follow-up, or description provided of those lost)
C. Follow-up rate $<\ldots \%$ (select an adequate $\%$ ) and no description of those lost

D. No statement

ASBO, adhesive small bowel obstruction; NA, not applicable.

Clearly, additional studies are warranted to further examine the use of water-soluble contrast agents, such as Gastrografin, in the conservative management of children with ASBO.

Treatment success was often affected by the age of the children is these studies. For example, the study by Vijay et $a l^{18}$ included patients from 0 to 13 years of age. The treatment success increased for children more than 1 year of age. The study by Akgur et $a l^{19}$ included patients from 1 month to 16 years of age. The investigators reported that the patients, 8 years of age and older, who received gridiron incisions for appendicitis in the 
Table 4 Newcastle-Ottawa quality assessment scale (case-control study)

\begin{tabular}{ll}
\hline First author (year) & $\begin{array}{l}\text { Bonnard } \\
\text { (2011) }\end{array}$ \\
\hline
\end{tabular}

\section{Selection}

1. Is the case definition adequate?

A. Yes, with independent validation

B. Yes, ie, record linkage or based on self reports

C. No description

2. Representativeness of the cases

A. Consecutive or obviously representative series of cases

B. Potential for selection biases or not stated

3. Selection of controls

A. Community controls

B. Hospital controls

C. No description

4. Definition of controls

A. No history of disease (endpoint)

B. No description of source

Comparability

1. Comparability of cases and controls on the basis of the design or analysis

A. Study controls for Gastrografin treatment for ABSO (select the most important factor.)

B. Study controls for any additional factor (this criteria could be modified to indicate specific control for a second important factor.)

Exposure

1. Assessment of exposure

A. Secure record (ie, surgical records)

B. Structured interview where blind to case/control status

C. Interview not blinded to case/control status

D. Written self report or medical record only

D. No description

2. Same method of ascertainment for cases and controls

A. Yes

B. No

3. Non-response rate

NA

A. Same rate for both groups

B. Non respondents described

C. Rate different and no designation

ASBO, adhesive small bowel obstruction; NA, not applicable.

first 3 months of the postoperative period had the greatest chance of overcoming obstruction non-operatively. In contrast, the patients who underwent their first surgery in the neonatal period, for a condition requiring a colonic pull-through, and the last surgery more than 18 months ago has the least chance of overcoming a bowel obstruction.
Our review has a number of limitations that warrant acknowledgment. First and foremost, all but one of the studies included in our systematic review had inherent limitations due to their retrospective design. Second, there was some between study variability in conservative treatment regimens that clearly had an impact on the findings. Aside from treatment success, there was also variability between studies in the types of outcomes assessed, making it difficult for us to comment further on other outcomes (although, unsurprisingly, conservative treatment was clearly associated with a shorter length of hospital stay and time to first feeding than operative treatment). Finally, only a small number of studies met the criteria for inclusion in our review. Ideally, additional, well-designed, prospective studies are needed to more comprehensively evaluate the place of conservative treatment for the management of ASBO in children.

In summary, we have reviewed the current literature reporting outcomes following conservative treatment for the management of ASBO in children. Although some children with ASBO will always require immediate surgery (ie, those with bowel strangulation), the available evidence suggests that comprehensive conservative treatment can be effective in a large proportion of cases. Further studies are needed to optimise conservative treatment strategies for children with ASBO.

Acknowledgements The authors thank Julie Crider for assistance with English language editing.

Contributors L-HL designed the study and wrote the protocol, managed the literature searches and analyses, undertook the statistical analysis, wrote the first draft of the manuscript; C-YL managed the references; $\mathrm{M}-\mathrm{HH}$ performed the analyses; D-FC performed research/study.

Funding This research received no specific grant from any funding agency in the public, commercial or not-for-profit sectors.

\section{Competing interests None.}

Provenance and peer review Not commissioned; externally peer reviewed.

Data sharing statement No additional data are available.

Open Access This is an Open Access article distributed in accordance with the Creative Commons Attribution Non Commercial (CC BY-NC 4.0) license, which permits others to distribute, remix, adapt, build upon this work noncommercially, and license their derivative works on different terms, provided the original work is properly cited and the use is non-commercial. See: http:// creativecommons.org/licenses/by-nc/4.0/

\section{REFERENCES}

1. Attard JA, MacLean AR. Adhesive small bowel obstruction: epidemiology, biology and prevention. Can J Surg 2007;50:291-300.

2. Dayton MT, Dempsey DT, Larson GM, et al. New paradigms in the treatment of small bowel obstruction. Curr Probl Surg 2012:49:642-717.

3. Menzies $D$, Ellis $\mathrm{H}$. Intestinal obstruction from adhesions-how big is the problem? Ann R Coll Surg Engl 1990;72:60-3.

4. Aguayo $\mathrm{P}, \mathrm{Ho} \mathrm{B}$, Fraser JD, et al. Bowel obstruction after treatment of intra-abdominal tumors. Eur J Pediatr Surg 2010;20:234-6.

5. El-Gohary Y, Alagtal M, Gillick J. Long-term complications following operative intervention for intestinal malrotation: a 10-year review. Pediatr Surg Int 2010;26:203-6.

6. Grant HW, Parker MC, Wilson MS, et al. Population-based analysis of the risk of adhesion-related readmissions after abdominal surgery in children. J Pediatr Surg 2006;41:1453-6. 
7. Festen C. Postoperative small bowel obstruction in infants and children. Ann Surg 1982;196:580-3.

8. Li MZ, Lian L, Xiao LB, et al. Laparoscopic versus open adhesiolysis in patients with adhesive small bowel obstruction: a systematic review and meta-analysis. Am J Surg 2012;204:779-86.

9. Vettoretto N, Carrara A, Corradi A, et al. Laparoscopic adhesiolysis: consensus conference guidelines. Colorectal Dis 2012;14:e208-15.

10. Van Der Krabben AA, Dijkstra FR, Nieuwenhuijzen M, et al. Morbidity and mortality of inadvertent enterotomy during adhesiotomy. Br J Surg 2000;87:467-71.

11. Branco BC, Barmparas G, Schnuriger B, et al. Systematic review and meta-analysis of the diagnostic and therapeutic role of water-soluble contrast agent in adhesive small bowel obstruction. $\mathrm{Br}$ J Surg 2010:97:470-8.

12. Miller G, Boman J, Shrier I, et al. Natural history of patients with adhesive small bowel obstruction. Br J Surg 2000;87:1240-7.

13. Williams SB, Greenspon J, Young HA, et al. Small bowel obstruction: conservative vs. surgical management. Dis Colon Rectum 2005;48:1140-6.

14. Seror D, Feigin E, Szold A, et al. How conservatively can postoperative small bowel obstruction be treated? Am J Surg 1993;165:121-5; discussion 125-6.

15. Fevang BT, Jensen D, Svanes K, et al. Early operation or conservative management of patients with small bowel obstruction? Eur J Surg 2002;168:475-81.

16. Feigin E, Kravarusic D, Goldrat I, et al. The 16 golden hours for conservative treatment in children with postoperative small bowel obstruction. J Pediatr Surg 2010;45:966-8.

17. Eeson GA, Wales $P$, Murphy JJ. Adhesive small bowel obstruction in children: should we still operate? J Pediatr Surg 2010;45:969-74.

18. Vijay K, Anindya $\mathrm{C}$, Bhanu $\mathrm{P}$, et al. Adhesive small bowel obstruction (ASBO) in children-role of conservative management. Med J Malaysia 2005;60:81-4.
19. Akgur FM, Tanyel FC, Buyukpamukcu N, et al. Adhesive small bowel obstruction in children: the place and predictors of success for conservative treatment. $J$ Pediatr Surg 1991;26:37-41.

20. Di Saverio S, Coccolini F, Galati M, et al. Bologna guidelines for diagnosis and management of adhesive small bowel obstruction (ASBO): 2013 update of the evidence-based guidelines from the world society of emergency surgery ASBO working group. World $\mathrm{J}$ Emerg Surg 2013;8:42.

21. Bonnard A, Kohaut J, Sieurin A, et al. Gastrografin for uncomplicated adhesive small bowel obstruction in children. Pediatr Surg Int 2011;27:1277-81.

22. Osifo OD, Ovueni ME. Is nonoperative management of adhesive intestinal obstruction applicable to children in a resource-poor country? Afr J Paediatr Surg 2010;7:66-70.

23. Nasir AA, Abdur-Rahman LO, Bamigbola KT, et al. Is non-operative management still justified in the treatment of adhesive small bowel obstruction in children? Afr J Paediatr Surg 2013; 10:259-64.

24. Joyce WP, Delaney PV, Gorey TF, et al. The value of water-soluble contrast radiology in the management of acute small bowel obstruction. Ann R Coll Surg Engl 1992;74:422-5.

25. Di Saverio S, Catena F, Ansaloni L, et al. Water-soluble contrast medium (gastrografin) value in adhesive small intestine obstruction (ASIO): a prospective, randomized, controlled, clinical trial. World $J$ Surg 2008;32:2293-304.

26. Feigin E, Seror D, Szold A, et al. Water-soluble contrast material has no therapeutic effect on postoperative small-bowel obstruction: results of a prospective, randomized clinical trial. Am J Surg 1996;171:227-9.

27. Abbas S, Bissett IP, Parry BR. Oral water soluble contrast for the management of adhesive small bowel obstruction. Cochrane Database Syst Rev 2007:CD004651. 